\title{
Segmentectomy...Because We Can or Because We Should?
}

\author{
Justin M. Karush, DO \\ Rush University Medical Center, Chicago, IL
}

Shortly after the United States signed the Paris Peace Accords in 1973, Drs. Faber and Jensik published the first series on segmental lung resection for the treatment of primary lung cancer. ${ }^{1}$ This study involved a 15 -year experience and questioned the standard of lobectomy at that time. In the nearly four decades that have followed, the question remains a source of great controversy. Data on the subject have been conflicting and lack in standardization and randomization. To date, the only published, randomized, controlled trial lumped segmentectomy and wedge resection together as sublobar resections, and demonstrated inferiority to lobectomy. ${ }^{2}$ Thus, lack of convincing data, along with technical considerations, has likely limited the use of segmentectomy.

Over the past decade, lung cancer screening has finally begun to gain favor. We are seeing an increase in the yield of clinical early-stage disease. Thus, the question as to whether we should spare parenchyma for these small $(\leq 2$ $\mathrm{cm}$ ) solid nodules, as well as for part solid or pure GGOs, is very relevant. It is in this arena that Dai et al. publish their retrospective analysis of patient-reported outcomes after VATS lobectomy versus VATS segmentectomy for earlystage lung cancer. ${ }^{3}$ The study included 110 patients (42 segments vs. 62 lobectomies) with peripheral, $\leq 2 \mathrm{~cm}$, and histologically confirmed lung cancers. The primary objective was to compare patient-reported symptom severity and functional status. These were both measured at baseline, during the immediate postoperative period (first 6 days), and at 4 weeks after discharge.

(C) Society of Surgical Oncology 2021

First Received: 6 October 2021

Accepted: 7 October 2021;

Published Online: 21 October 2021

J. M. Karush, DO

e-mail: justin_m_karush@rush.edu
The authors found the top five symptoms after lung cancer surgery were cough, shortness of breath, pain, fatigue, and disturbed sleep. The fop five functional impairments were work, walking, general activity, enjoyment of life, and mood. Their analysis revealed essentially no difference in any of these reported outcomes at any of the measured timepoints between groups. One exception was the less disturbed sleep in the lobectomy group. Additionally, there were no differences in operative times, length of stay, chest tube duration, pain medicine requirement, or complications. The authors concluded that if oncologic outcomes are assumed to be equivalent, this analysis supports the use of segmentectomy over lobectomy.

The main limitation of this analysis pertains to the preoperative characteristics of the patients included. Specifically young (mean age 53 years), predominantly never-smokers $(85 \%)$, with nearly perfect pulmonary function (median DLCO 95\%) and predominantly GGOs/part solid nodules were included. It is reasonable to hypothesize that patients with normal pulmonary function do not stand to benefit, from a clinical perspective, as much from segmentectomy as those who are high risk (i.e., predicted post op DLCO $\leq 40$ ). Thus, patient-reported outcomes would be less likely to differ. While the authors concluded that these results support segmentectomy, in light of the patient selection I do not share this conclusion. The equivalent outcomes actually still support lobectomy in patients with normal pulmonary function, which I think is extremely valuable information when making decisions on which operation to offer such a patient.

Additionally, the authors reference the recently published JCOG0804, which compared wedge resection and segmentectomy for pure GGOs and part solid GGOs with consolidation to tumor ratio $\leq 0.25 .{ }^{4}$ The majority of these sublobar resections were wedge resections, and they demonstrated excellent local control and relapse-free survival. Because pure GGOs made up $80 \%$ of the 
segmentectomy cohort in this current study, one could argue that the greatest improvement in patient-reported outcomes could be from comparison of wedge resection versus segmentectomy, which could be the topic of future research.

Overall the debate between segmentectomy and lobectomy continues as we await the results of two prospective, randomized trials (CALGB-140503 and JCOG0802/ WJOG4607L). We do, however, have several retrospective studies that suggest equivalency between the two approaches for tumors $\leq 2 \mathrm{~cm}$ and with a margin-to-tumor ratio $>1 .^{5,6}$ Furthermore, the recent growth of robotics in thoracic surgery also may play a role in the choice of segmentectomy over lobectomy as many adopters of robotics, including myself, argue that the technology improves their ability to dissect out segmental anatomy compared with VATS. I believe that if these RCTs demonstrate what the retrospective data suggest, then in an era where we are identifying more and more early disease, we also will be able to offer surgery to a broader range of patients for whom lobectomy may not be an option.

DISCLOSURE The author declares no conflicts of interest.

\section{REFERENCES}

1. Jensik RJ, Faber LP, Milloy FJ, Monson DO. Segmental resection for lung cancer. A fifteen-year experience. $J$ Thorac Cardiovasc Surg. 1973;66:563-72.

2. Ginsberg RJ, Rubinstein LV. Randomized trial of lobectomy versus limited resection for T1N0 non-small cell lung cancer. Lung Cancer Study Group. Ann Thorac Surg. 1995;60:615-22.

3. Dai W, Chang S, Pompili C, et al. Early postoperative patientreported outcomes after thoracoscopic segmentectomy versus lobectomy for small-sized non-small cell lung cancer. Ann Surg Oncol. 2021. https://doi.org/10.1245/s10434-021-10946-7.

4. Suzuki K, Watanabe SI, Wakabayashi M, et al. A single-arm study of sublobar resection for ground-glass opacity dominant peripheral lung cancer. J Thorac Cardiovasc Surg. 2020;S0022-5223(20): 33043-9.

5. Okada M, Koike T, Higashiyama M, et al. Radical sublobar resection for small-sized non-small cell lung cancer: a multicenter study. J Thorac Cardiovasc Surg. 2006;132:769-75.

6. Carr SR, Schuchert MJ, Pennathur A, et al. Impact of tumor size on outcomes after anatomic lung resection for stage 1A non-small cell lung cancer based on the current staging system. $J$ Thorac Cardiovasc Surg. 2012;143:390-7.

Publisher's Note Springer Nature remains neutral with regard to jurisdictional claims in published maps and institutional affiliations. 